Case Report

\title{
Evaluation of Lower Anterior Facial Height and Incisors Vertical Dimension after Class II Division 1 Treatment
}

\author{
Elih Sayuti $^{\text {a }}$ Deni Sumantri Latif ${ }^{\text {a }}$ \\ ${ }^{\text {a }}$ Department of Orthodontics, Faculty of Dentistry Universitas Padjadjaran, Indonesia
}

\begin{abstract}
Introduction: Orthodontic treatment of class II division 1 malocclusion by extracting the maxillary first premolar causes vertical dimensional change is still a matter of debate. The purpose of this research was to determine the vertical changes of the lower anterior facial height and maxillary incisor vertical dimensions in class II division 1 malocclusion after orthodontic treatment with Edgewise technique.

Materials and Methods: This study was conducted on the cephalometry of 24 patients before and after orthodontic treatment with inclusion criteria as follows: Angle Class II division 1 malocclusion, aged 18-30 years old. Measurements were taken for the lower anterior facial height (ANS - Me) and maxillary incisor vertical dimensions by performing an Upper Anterior Dental Height (UADH). Data analysis used was the Wilcoxon test for unpaired data.

Results: The result of $\mathrm{p}$-value $=0.195>0.05$ for lower anterior face height showed no significant difference; and p-value $=0.878>0.05$ for UADH also showed no significant difference. Conclusion: Orthodontic treatment for class II division 1 malocclusion with the removal of two premolars does not change the lower anterior facial height and maxillary incisor vertical dimensions.
\end{abstract}

Keywords: Lower anterior facial height, incisors vertical dimension, Class II division 1.

\section{Introduction}

Class II division 1 malocclusion often called distocclusion, with protrusive characteristics of the anterior teeth, large overjet, deep overbite, and convex profile. Besides abnormal molar relationship, class II division 1 malocclusion is often complicated by skeletal dysplasia in the anteroposterior and vertical directions, and muscle dysplasia. ${ }^{1,2}$ Class II division 1 malocclusion may occur due to discrepancy of the maxillary and mandibular relations in anteroposterior as a result of retrognathic mandibular and normal maxillary, normal mandibular and prognathic maxillary, and a combination of prognathic maxillary and retrognathic mandibular. Retrognathic or mandibular deficiency can occur in absolute terms in a small mandibular size, or relative deficiency, when the mandibular size is normal but relatively in the posterior position to the maxillary. Both show a class II malocclusion relationship marked with an ANB angle which is higher than $4^{\text {o }} .^{1-5}$

Class II division 1 malocclusion treatment in adult often performed in the premolars as premises alternatively in providing space to correct large overjet by retracting maxillary anterior teeth. The effect of premolar extraction on class II division 1 malocclusion treatment can lead to an anti-clockwise mandibular rotation, resulting in a vertical dimensional decrease.

In orthodontic treatment, incisolabial relationships are often altered due to the craniofacial growth and development factors, and also due to the treatment procedures such as premolar extraction, maxillary incisor retraction, and also intermaxillary elastics and extraoral appliances use. It is still a matter of debate whether the premolar extraction will affect the vertical dimensional changes in the lower anterior facial height and vertical dimensional of incisors or not. ${ }^{6,7,8}$ Cusinamo et al. suggested that premolar extraction did not increase facial height. ${ }^{9,10}$ Instead, research conducted by Wyatt proved that premolar retraction followed by anterior teeth retraction in orthodontic treatment of class II division 1 malocclusion might cause posterior displacement of the condyle and disc transfer into the anterior thus causing vertical dimension changes. 
Based on the above descriptions we are interested in researching the vertical dimension changes of lower anterior facial height and incisors in class II division 1 malocclusion orthodontic treatment with Edgewise technique by extraction of two maxillary premolars. ${ }^{9,10}$

\section{Materials And Methods}

The study sample was taken from class II division 1 malocclusion patients that had been treated by orthodontists at Orthodontic Clinics of the Faculty of Dentistry Universitas Padjadjaran. Twenty-four X-ray images of lateral cephalometry before and after treatment were selected with the following criteria: (1) Aged more than 15 years old; (2) Male and female; (3) Class II division 1 malocclusion; (4) Had medical record data, cephalometry of lateral radiograph before and after treatment; (5) Treated with compromised Edgewise technique by extraction of two maxillary premolars; (6) Treated with no functional or extraoral appliance. Cephalometric tracing was performed manually with an intra-examiner calibration on transparent acetate paper. The reference points of the current study were: Nation (N), Sella turcica (S), Menton (Me), Gonion (Go), Gnathion (Gn), Spina Nasalis Anterior (SNA), Posterior Nasal Spine (PNS). The cephalometric lines and planes were: The palatal plane (ANS-PNS), the mandibular plane (G0-Gn), the occlusal plane which is a line above the occlusal of the mandibular molars at the occlusion with the incisal edges of the first mandibular incisor. A Lower Anterior Facial Height (LAFH) is the vertical distance of the anterior nasal spine (ANS) to the menton (Me) point, the Upper Anterior Dental Height (UADH) is the perpendicular distance from the incisal of the maxillary first incisor against the palatal plane. ${ }^{11}$ The cephalometric measurements used in this research is shown in Table 1. Figure 1 shows the location of the landmarks and other extraoral measurements taken on the research.

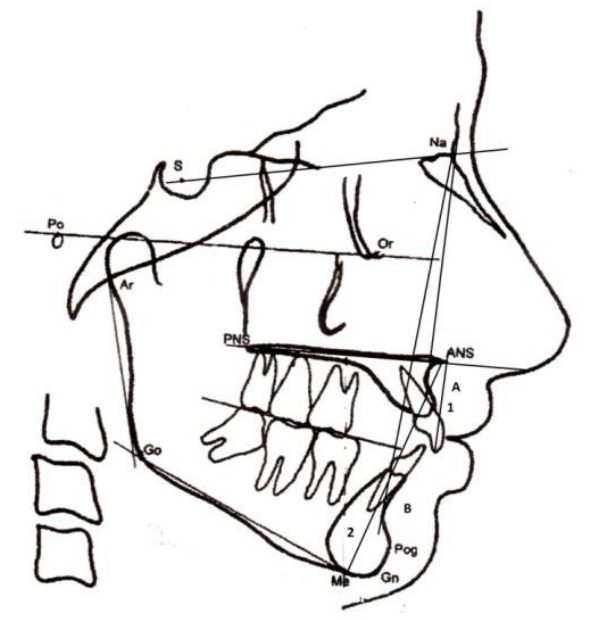

Figure 1. Lateral cephalometric landmark: (1) UADH; (2) LAFH

Table 1. Definition of cephalometric measurements

\begin{tabular}{|c|c|l|}
\hline No & Measurement & \multicolumn{1}{c|}{ Definition } \\
\hline 1 & SNA & $\begin{array}{l}\text { The anteroposterior position of point A relative to the } \\
\text { anterior cranial base }\end{array}$ \\
\hline 3 & ANB & $\begin{array}{l}\text { The anteroposterior position of point B relative to the } \\
\text { anterior cranial base }\end{array}$ \\
\hline 4 & $\begin{array}{l}\text { Occlusal } \\
\text { plane } \\
\text { maxillarye and mandibular bases }\end{array}$ \\
\hline 5 & LAFH & $\begin{array}{l}\text { Line through the occlusal surface of the mandibular } \\
\text { molars at the occlusion with the incisal edges of the } \\
\text { mandibular first incisor }\end{array}$ \\
\hline
\end{tabular}




\begin{tabular}{|c|c|l|}
\hline & & anterior nasal spine (ANS) to the point of menton (Me) \\
\hline 6 & UADH & $\begin{array}{l}\text { Upper anterior dental height is the maxillary incisor height } \\
\text { is the perpendicular distance from the incisal of the } \\
\text { maxillary first incisor against the palatal plane }\end{array}$ \\
\hline
\end{tabular}

\section{Statistical Analysis}

Data from the measurements in the evaluation of vertical dimension of lower anterior facial height and vertical dimension of incisors in class II division 1 treatment was analysed by a statistical test. The difference between before and after treatment was determined with Wilcoxon test. P-value $<0.05$ was considered as significant.

\section{Results}

All patients have class II division 1 dentoskeletal - skeletal relationships were based on angle measurements of SNA, SNB, and ANB prior to treatment. The mean of SNA was $83.34^{\circ}$, indicated normal maxillary and anterior cranial relationship. Mean of SNB was $77.60^{\circ}$, indicated mandibular recognition. And mean of the ANB was $5.80^{\circ}$, indicated class II malocclusion.

Table 2. Cephalometric measurement

\begin{tabular}{|c|c|c|c|}
\hline No & Measurement & Average & SD \\
\hline 1 & SNA $\left(^{\circ}\right)$ & 83.34 & 4.34 \\
\hline 2 & SNB $\left(^{\circ}\right)$ & 77.60 & 3.61 \\
\hline 3 & ANB $\left(^{(}\right)$ & 5.80 & 1.94 \\
\hline
\end{tabular}

Table 3. Cephalometric measurement of UADH and LADH

\begin{tabular}{|c|c|c|c|c|c|c|}
\hline No & Parameter & & & $\mathrm{N}=25$ & & \\
\hline & & $\begin{array}{c}\text { Before } \\
(\mathrm{mm})\end{array}$ & $\begin{array}{l}\text { After } \\
(\mathbf{m m})\end{array}$ & $\begin{array}{c}\text { Difference } \\
(\mathbf{m m})\end{array}$ & SD & P-value \\
\hline 1 & LAFH & 68.13 & 66.38 & 1.75 & 3.35 & 0.206 \\
\hline 2 & UADH & 30.17 & 30.33 & 0.16 & 1.61 & 0.878 \\
\hline
\end{tabular}

Notes: *significant at $\mathbf{p}<0.05$

The mean, standard deviation, and p-value for cephalometric measurement were found in Table 1 . In the vertical dimension of lower anterior facial height measurement, there was a decrease of $1.75 \mathrm{~mm}$ with pvalue $=0.206(\mathrm{p}>0.05)$ which showed no significant change. In the measurement of upper anterior dental height, there was found an insignificant increase of $0.16 \mathrm{~mm}$ with p-value $=0.878(\mathrm{p}>0.05)$ (Table 2). Evaluation of orthodontic treatment of class II division 1 malocclusion by retraction showed that premolar extraction did not decrease vertical dimensions of lower anterior facial height and vertical dimensions of the maxillary incisors.

\section{Discussion}

This study was aimed to evaluate vertical dimensional changes in the lower anterior facial height and vertical dimensions of the maxillary incisor in the treatment of class II division 1 malocclusion by extraction of the two maxillary premolars using the Edgewise technique. Vertical dimensional changes can affect the aesthetic smile of the patient due to changes in the position of the maxillary teeth, occlusal plane inclination, and craniofacial growth direction. ${ }^{10}$

The purpose of orthodontic treatment is to obtain a normal dental arrangement and good occlusion contact to achieve the ideal occlusion function and aesthetics facial appearance as well as stable treatment results. Compromised orthodontic treatment is a frequent treatment in class II division 1 malocclusion cases in adults aside from orthognathic surgical treatment. In compromised treatments, only malpositioned teeth were repaired without improving skeletal abnormalities. ${ }^{1-3}$ 
Characteristics of class II division 1 malocclusion are protrusive incisors and large overjet that causes convex facial profile. Premolar extraction is aimed at providing space to correct tooth crowding and inclination. According to Newton's Law, anterior retraction to the palatal will cause posterior tooth movement anteriorly. ${ }^{3}$ Mesial drifting of the unexpected molar is called anchorage loss. ${ }^{1-3}$ Anchorage loss or mesial drifting can cause vertical dimension changes. Therefore, adequate anchorage control is needed to prevent anchorage loss. Maintaining an anchorage can prevent temporomandibular disorder caused by vertical dimension changes. Previous studies showed that first maxillary molar with maximum anchorage experienced mesial migration as much as $30 \%$ towards the extracted teeth space. ${ }^{12-15}$

Prior to the anterior retraction, median line correction should be performed first so that the force received in both sides will be equal. An unequal anterior retraction can produce an unequal vertical force on both sides. Thus causing a unilateral vertical force that leads to asymmetric dental arches and asymmetric loss of anchorage. ${ }^{16}$ Vertical forces need to be taken into consideration to control the vertical dimensions during space closure.

In the current study, the patients were treated using an Edgewise technique by reinforced anchoring involving the second molar. Such anchoring prevents mesial drifting of the molar. Although, some studies have reported that the second molar reinforcement anchorage is not effectively used in retracting the anterior teeth in the treatment of class II division 1 malocclusion. ${ }^{13,15,17}$ In the current study, there was no vertical change in the lower anterior facial height and vertical dimensions of the incisor in the treatment of class II division 1 malocclusion.

The results of our study did not support some researchers findings suggested that extraction of the first premolar on orthodontic treatment can cause vertical dimension decline which may further cause TMJ disorders. ${ }^{10,13} \mathrm{Al}$ Nimri et al. stated that there was an increase in total anterior facial height, lower anterior facial height and the posterior facial height in the treatment of class II division 1 malocclusion, both at the extraction of the two first premolars and the two second mandibular premolars. ${ }^{18}$ A study conducted by Souto et al. on vertical dimensional changes in class II division 1 orthodontic treatment with premolars extraction showed that there was a significant change in vertical position of the maxillary central incisor, the vertical position of the maxillary first molars and the Sn-Palatal plane. ${ }^{10}$

The current study, however, was consistent with the study conducted by Cusinamo et al. which stated that there was no difference in the facial height before and after treatment with premolar retraction in hyperdivergent patients. ${ }^{6}$ Some findings also proved no significant vertical dimension change in the treatment of class I malocclusion with or without retraction. ${ }^{19}$ Other studies also reported that extraction of 4 premolars had no specific effect on the vertical dimension compared with non-extraction cases. ${ }^{20}$ Likewise, Krirschneck reported that many studies have proved that there were no significant vertical dimensional changes in both extraction and non-extraction cases. ${ }^{21,22}$ Although, a study conducted by Kumari suggested that there was a clinically significant increase in the $\mathrm{N}$-Me distance $(4 \mathrm{~mm})$ compared to treatment without extraction. $^{23}$

Our study found that there was no vertical change in the lower anterior facial height and vertical dimensions of the incisors in the treatment of class II division 1 malocclusion. This result is likely due to proper anchoring and good vertical control during anterior teeth retraction.

\section{Conclusion}

Based on the results of our present study, it can be concluded that the treatment of class II division 1 malocclusion with premolar extraction does not cause vertical dimensional changes in the lower anterior facial height and vertical dimensions of the incisors.

\section{References}

1. Proffit WR, Fields HW Jr., Sarver DM. Contemporary Orthodontics. $4^{\text {th }}$ ed. London: Elsevier Health Science; 2006. p. 3-8.

2. Bishara SE. Textbook of Orthodontics. $1^{\text {st }}$ ed. Philadelphia: W.B. Saunders Co.; 2001. p. 416-7.

3. Graber L, Vanarsdall R, Vig K. Orthodontics: Current Principles and Techniques. $5^{\text {th }}$ ed. St. Louis: Mosby-Elsevier; 2012. p. 429-36.

4. Premkumar S. Biomechanics of Tooth Movement in Prep Manual for Undergraduates Orthodontics. New Delhi: Elsevier; 2008. p. 263-71. 
5. Rakosi T. An Atlas and Manual of Cephalometric Radiography (Wolfe Medical Atlases). St. Louis: Mosby-Elsevier; 1982. p.54-8.

6. Bishara SE, Cummins DM, Jakobsen JR, Zaher AR. Dentofacial and soft tissue changesin Class II division I cases treated with and without extraction. Am J Orthod Dentofacial Orthop. 1995; 107: 28-37. DOI: $10.1016 / \mathrm{s} 0889-5406(95) 70154-0$

7. Taner-Sarisoy L, Darendeliler N. The influence of extraction orthodontic treatment on craniofacial structures evaluation according to two deifferent factors. Am J Orthod Dentofacial Orthop. 1999; 115: 508-14. DOI: $10.1016 / \mathrm{s} 0889-5406(99) 70272-6$

8. Stagger JA. Vertical control changes following first premolar extraction. Am J Orthod Dentofacial Orthop. 1994; 105: 19-24. DOI: 10.1016/S0889-5406(94)70095-8

9. Zafarmand AH, Zafarmand MM. Premolar Extraction in Orthodontics: Does it have any effect on patient"s facial height?. J Int Soc Prev Community Dent. 2015; 5: 64-8. DOI: 10.4103/22310762.151980

10. Souto M, Maeda PM, Scavone-Junior H, Ferreira RI, Vellini-Ferreira F. Vertical Cephalometric Changes after Treatment of Class II Division 1 Malocclusion. Rev Odontol Univer Cid Sao Paulo. 2008; 20: 6-13.

11. Sivakumar A, Valiathan A. Cephalometric assessment of dentofacial vertical changes in class I subject treated with and without extraction. Am J Orthod Dentofacial Orthop. 2008; 133: 869-75. DOI: 10.1016/j.ajodo.2006.05.041

12. Kim TK, Kim JT, Mah J, Yang WS, Baek SH, First or Second Premolar Extraction Effection Facial Vertical Dimension. Angle Orthod. 2005; 75: 177-82. DOI: $\underline{10.1043 / 0003-}$ 3219(2005)075<0173:FOSPEE >2.0.CO;2

13. Kocadereli I. The effect of first premolar extraction on vertical dimension. Am J Orthod Dentofacial Orthop. 1999; 116: 41-5. DOI: 10.1016/s0889-5406(99)70301-x

14. Upadhyay M, Yadav S, Patil S. Mini Implant Anchorage for Enmassa Retraction on Maxillary Anterior teeth: Aclinical Cephalometric Study. Am J Orthod Dentofacial Orthop. 2008; 134: 803-10. DOI: 10.1016/j.ajodo.2006.10.025

15. Ibrahim G. Comparison of the Amount of Anchorage Loss of the Molar with and without the Use of Implant Anchorage during Anterior Segment Retradtion Combined with Alveolar Corticotomies. J Dent Health Oral Dis Ther. 2015; 2: 1-7. DOI: 10.15406/jdhodt.2015.02.00067

16. Nelson ZL, Moon. Craniofacial Growth, the Cellular Basis of Tooth Movement and Anchorage. In: Mitchell L. An Introduction to Orthodontics. $3^{\text {th }}$ ed. New York: Oxford University Press; 2007. p. 45-7.

17. Londhe SM, Kumar P, Mitra R, Kotwal A. Efficacy of Second Molar to Achieve Anchorage Control in Maximum Anchorage Cases. Med J Armed Forces India. 2010; 66: 220-4. DOI: 10.1016/S03771237(10)80041-3

18. Al-Nimri KS. Vertical Change in Class II division 1 Malocclusion after Premolar Extractions. Angle Orthod. 2006; 76: 52-8. DOI: 10.1043/0003-3219(2006)076[0052:VCICID]2.0.CO;2

19. Hayasaki SM, Castanha Henriques JF, Janson G, de Freitas MR. Influence of extraction and non extraction orthodontic treatment in Japanese-Brazilians with Class I and Class II division 1 malocclusions. Am J Orthod Dentofacial Orthop. 2005; 127: 30-6. DOI: 10.1016/j.ajodo.2003.10.043

20. Kouvelis G, Dritsas K, Doulis I, Kloukos D, Gkantidis N. Effect of orthodontic treatment with 4 premolar extractions compared with nonextraction treatment on the vertical dimension of the face: A systematic review. Am J Orthod Dentofacial Orthop. 2018; 154: 175-87. DOI: 10.1016/j.ajodo.2018.03.007

21. Kirschneck C, Proff P, Reicheneder C, Lippold C. Short-term effects of systematic premolar extraction on lip profile, vertical dimension and cephalometric parameters in borderline patients for extraction therapy-a retrospective cohort study. Clin Oral Investig. 2016; 20: 865-74. DOI: 10.1007/s00784-015$\underline{1574-5}$

22. Gkantidis N, Halazonetis DJ, Alexandropoulos E, Haralabakis NB. Treatment strategies for patients with hyperdivergent Class II Division 1 malocclusion: is vertical dimension affected? Am J Orthod Dentofacial Orthop. 2011; 140: 346-55. DOI: 10. 1016/j.ajodo.2011.05.015

23. Kumari M, Fida M. Vertical facial and dental arch dimensional changes in extraction vs. non-extraction orthodontic treatment.J Coll Physicians Surg Pak. 2010; 20: 17-21. DOI: 01.2010/JCPSP.1721 